\title{
A gênese da geopolítica e sua difusão na história mundial
}

\author{
The genesis of geopolitics \\ and its diffusion in world history
}

Rev. Bras. Est. Def. v. $5, \mathrm{n}^{\circ} 1$, jan./jun. 2018, p. 19-40

DOI: $10.26792 /$ RBED.v5n1.2018.75055

ISSN 2358-3932

\section{ÉRIKA LAURINDA AMUSQUIVAR RODRIGO DUARTE FERNANDES DOS PASSOS}

\section{INTRODUÇÃO}

A discussão sobre a geopolítica começou a ser difundida exponencialmente no mundo contemporâneo sobretudo a partir das Grandes Guerras Mundiais. As transformações das estratégias políticas nessa época foram fundamentais para redesenhar o quadro de forças entre as potências, sobretudo na Europa. No entanto, a compreensão da geopolítica não está associada apenas a uma dimensão espacial, mas a uma conjugação do território com a disputa de poder. Para se alcançar a diretriz geopolítica de um Estado é necessário identificar os componentes políticos que o compõem, levando em consideração as especificidades de tempo e espaço, ou seja, quando se produz tal política e qual o seu lugar.

A origem da palavra geopolítica está associada ao desenvolvimento de um pensamento político escandinavo datado da virada do século XIX para o século XX pelo cientista político, sociólogo e jurista sueco Johan Rudolf Kjellén. O termo nasce na Suécia, porém a discussão ganha peso em outros países, a partir de um contexto histórico de disputas territoriais não só na região escandinava, mas também em escala mundial, momento em que a história era marcada por grandes transformações políticas, econômicas e culturais. O termo "geopolítica" ganhou plena notoriedade a partir dos desdobramentos da Primeira Guerra Mundial, pautando as estratégias dos Estados na reformulação de suas políticas a partir de definições espaciais, sobretudo das grandes potências. Dois dos grandes países que passaram a

\footnotetext{
Érika Laurinda Amusquivar - Doutora em Ciência Política pelo Instituto de Filosofia e Ciências Humanas (IFCH) da Unicamp.

Rodrigo Duarte Fernandes dos Passos - Doutor em Ciência Política pela Universidade de São Paulo.
} 
utilizar amplamente o conceito foram a Alemanha e a Itália - e pautaram suas políticas no nazismo e fascismo, respectivamente.

Desta maneira, a geopolítica - enquanto definição conceitual - passou a ser utilizada pelos acadêmicos de modo a compreender a relação entre a lógica de poder dos Estados a partir da demarcação dos territórios e as características geográficas aos quais esses atores dispunham; e pelos estadistas, uma vez que lhes assegurou uma primazia política, econômica e militar por meio da expansão da estratégia do poder territorial. O conceito, portanto, passou a chamar a atenção, pois sua aplicabilidade tornou-se fundamental para a história, uma vez que sua inserção às vésperas das Guerras Mundiais permitiu inovar as estratégias políticas dos Estados e, portanto, a lógica de poder implementada nesse novo contexto do século XX.

Nesse artigo, portanto, iremos analisar a origem do conceito de geopolítica de acordo com a formulação kjelliana em um primeiro momento e como esse ganhou destaque na formulação da estratégia dos países, sobretudo os adeptos à tradição germanófila, no período do nazismo alemão. O objetivo desse texto é observar a trajetória do conceito e apontar como o mesmo expressa um conteúdo histórico e, sobretudo, político. Para tanto, será resgatado o momento histórico em que a geopolítica emerge até os momentos decisivos da expansão nazista na Alemanha - lugar em que a geopolítica ganha força e se expande até a Segunda Guerra Mundial. O artigo buscará compreender como a geopolítica ganha notoriedade em dois pensadores geopolíticos: Rudolf Kjellén e Karl Haushofer, na medida em que suas respectivas trajetórias estão ligadas à expansão da doutrina geopolítica na Europa do começo do século XX.

\section{A ORIGEM DO CONCEITO DE GEOPOLÍTICA EM KJELLÉN}

O termo geopolítica aparece pela primeira vez em um artigo de 1899 na revista sueca de tradição conservadora $Y$ mer. O artigo sobre as fronteiras da Suécia, intitulado Studier öfver Sveriges politiska Gränser ${ }^{1}$ (Estudos sobre os limites políticos da Suécia, em tradução livre), foi escrito pelo cientista político, jurista e sociólogo Johan Rudolf Kjellén, que buscou lapidar uma nova área do conhecimento no campo da Geografia. No entanto, apesar de Kjellén ter apresentado o conceito no final do século XIX, ele o discutirá melhor em 1916 no seu livro Staten som livsform (Estado como forma de vida, em tradução livre). Nesse livro, Kjellén denomina a geopolítica como

o estudo do Estado como organismo geográfico, isto é, como fenômeno localizado em certo espaço da Terra - logo, do Estado como país, como território, como região ou, mais caracteristicamente, como domínio político (reich) (Kjellén 1924 apud Couto e Silva 1967, 160). 
A geopolítica por definição compreende, portanto, o Estado como fenômeno do espaço. Também é definida enquanto um novo subcampo da disciplina de Geografia responsável pelo estudo do Estado como organismo geográfico, isto é, como um fenômeno localizado em um certo território (Couto e Silva 1967). Seu objeto não é o estudo geográfico do país no que se refere à geografia física ou à geografia humana, mas exclusivamente ao território como organização política, isto é o reich (Backheuser 1952).

Para se compreender mais detalhadamente o conceito da geopolítica, é preciso estabelecer uma análise do momento histórico em que o mesmo foi cunhado. Para tanto, a trajetória do autor é crucial para o entendimento de suas posições políticas e ideológicas. Concomitantemente, o momento histórico que passava a Suécia também é fundamental, visto que, em princípio, a análise geopolítica de Kjellén se refere ao país de origem. O pensador sueco também se preocupava com a política internacional, o que ajuda a compreender o conceito a partir das transformações políticas dos Estados na virada do século XIX para o XX.

Johan Rudolf Kjellén nasce em 1864 na Suécia, com uma formação luterana advinda de seu pai, um pároco na cidade de Torsö. Tendo nascido e crescido em um contexto de modernização sueca, fruto da Revolução Industrial e sob o Regime do Reino da Suécia e Noruega, Kjellén ingressou em 1880 na Universidade de Uppsala, e sua formação em Ciência Política fora determinante para a sua posição política mais conservadora, uma vez que seus estudos seguiam a linha da interpretação do caráter jurídico-constitucional do Estado (Holdar 1992). Durante onze anos em Uppsala se tornou PhD em Ciência Política em 1891. Ao se formar, foi contratado pela mesma Universidade como professor assistente na área de Ciência Política e Geografia entre 1890-1893. Posteriormente foi catedrático de Teoria do Estado na Universidade de Gottemburgo de 1901 a 1916 (Mello 1997). Como tinha pouca experiência na área da geografia, Kjellén buscou intensificar seus estudos e, dessa maneira, começou a ministrar palestras sobre questões contemporâneas as quais incitavam à pesquisa na área da geografia. Como também foi colunista e comentarista em um jornal conservador sueco intitulado Svenska Dagbladet (Diário Sueco, em tradução livre), as análises que publicava o ajudaram a pesquisar sobre a política conjuntural nacional e internacional. Assim, a aproximação dessas duas áreas do conhecimento - política e geografia -, juntamente com o acompanhamento das notícias políticas conjunturais de seu país, foi crucial para marcar seus estudos tanto na dimensão geográfica quanto na política, daí o termo cunhado mais tarde de geopolítica (Lewin 2008). Não se tratava, no entanto, de juntar política com geografia, mas de dar um novo olhar para a política, de modo a concebê-la em decorrência das condições geográficas (Couto e Silva 1967, 161). 
Além de sua atuação no campo acadêmico, Kjellén também se tornou um importante político e jurista. Sua trajetória política também ajudou a disseminar o conceito de geopolítica. Durante 1905 a 1908, e depois entre 1911 a 1917, cumpriu dois mandatos como membro da Câmara do Parlamento Sueco (Almagià 1933) com ideias conservadoras, sobretudo em relação à política nacional sueca. A aproximação com questões da política da Suécia o influenciou de modo a posicionar suas ideias a partir de um prisma nacionalista (Holdar 1992). Em meados do século XIX, a Suécia travou uma disputa com a Noruega, de modo que a união política entre Noruega e Suécia estabelecida fosse contestada pela primeira (Lees-Smith 1923). Kjellén defendia a primazia da Suécia, e sua preocupação excessivamente nacionalista fez com o que jurista sueco escrevesse diversos livros que discutiam a estratégia sueca frente às de outros países.

Kjellén funda nos estudos interdisciplinares entre Ciência Política e Geografia uma análise mais profunda sobre a região escandinava, sobretudo na interpretação do papel da Suécia nas articulações e reformulações políticas da região. Em muitos de seus escritos, o autor menciona a Suécia como um país estratégico na região nórdica, uma vez que seus atributos geográficos permitiam se proteger contra as ameaças provenientes de outros países, especialmente a Rússia, considerada como uma grande potência rival, seja por sua extensão territorial considerável, seja por suas posições políticas expansionistas² (Kjellén 1912, 1913, 1915). É nesse contexto que Kjellén desenvolverá uma leitura favorável quanto à aproximação estratégica com a Alemanha, que mais tarde seria o caminho aberto para que suas ideias pudessem ser disseminadas em âmbito mundial. Tanto que seus escritos remetem à importância da Alemanha para a redefinição de uma política mais assertiva também na região escandinava. Sem o papel alemão, a Europa seria dominada pelo perigo russo, segundo sua interpretação (Kjellén 1905, 15). Inclusive no livro Världskrigets politiska problem (1915) Kjellén chega a citar o seu artigo Den ryska faran de 1913 (O Perigo Russo, em tradução livre) para reforçar as configurações espaciais da Rússia, bem como sua estratégia nacionalista.

Diante da constatação de que a Alemanha era um país estratégico, seus escritos não tiveram grande repercussão na Suécia. Apesar de ter lecionado em duas universidades importantes - Uppsala e Gottemburgo - devido a sua conduta nacionalista durante a construção de seu pensamento enquanto geopolítico, Kjellén durante muito tempo foi rejeitado pela comunidade acadêmica e política escandinava. Isso porque muito da construção de suas obras manifestava uma forte influência alemã, a qual mais tarde foi um dos principais pilares para a estratégia da Alemanha para a definição da política estratégica das duas Guerras Mundiais, enquanto que a Suécia 
tentava permanecer neutra durante os conflitos. Desse modo, a notoriedade do pensamento de Kjellén aparecerá de forma mais contundente fora do território sueco, apesar de boa parte de seus estudos enaltecerem a autonomia de seu país de origem.

\section{A IMPORTÂNCIA DO PENSAMENTO KJELLIANO PARA A HISTÓRIA DA GEOPOLÍTICA}

Para Rudolf Kjellén, a necessidade de se criar uma Ciência Política sistematizada baseada na visão estadocêntrica permitiu ao jurista sueco uma inovação nos estudos tanto da ciência política quanto da geografia. A busca pela interpretação dos rumos da política mundial, tendo as grandes potências como principais atores do rearranjo político foi uma das forças motrizes para que seu pensamento sobre a geopolítica pudesse se desenvolver. O conceito de geopolítica, apesar de ter aparecido pela primeira vez em 1899, será plenamente desenvolvido em dois livros que se destacaram. O primeiro, intitulado Stormakterna (As Grandes Potências, em tradução livre) foi publicado pela primeira vez em sueco em 1900, desdobrando-se em três publicações revisadas. A primeira edição revisada data de 1911 a 1913 (Stormakterna I-V; As grandes potências I-V, em tradução livre); a segunda data de 1914 (Samtidens Stormakter; As grandes potências contemporâneas, em tradução livre) e a última em 1920, Stomakterna och Värdskrisen; As grandes potências e a crise mundial, em tradução livre (Holdar 1992, 308).

Suas obras também ganharam notoriedade na Alemanha. A tradução nesse país rendeu 22 edições entre 1914 e 1930, prefaciadas pelo alemão Karl Haushofer. O segundo livro, Staten som livsform (Estado como uma forma de vida, em tradução livre) (1916), ganhou destaque quando fora publicado também para a língua germânica (Der Staat als Lebensform ou Estado como forma de vida, em tradução livre) em 1917 (Holdar 1992, 310) cujo trecho evidenciava: "Sua ala esquerda não é a geografia, mas a geopolítica; seu assunto não é do país, mas sempre e exclusivamente da organização política penetrada pela terra, ou seja, o território” (Kjellén 1924, 42, tradução livre). Ambas as obras tinham como convergência o estudo do Estado, mais especificamente as grandes potências. O conceito de geopolítica ganhou espaço, dessa maneira, a partir das análises que Kjellén propunha sobre o Estado.

Uma das importantes premissas que Kjellén defende é compreender o Estado como um organismo vivo ou, conforme o título de seu livro menciona, como uma forma de vida - seja enquanto uma forma orgânica ou como uma analogia a um organismo (Holdar 1992, 310). Para que Kjellén pudesse sustentar essa ideia, a leitura de obras de alguns pensadores teve suas 
respectivas contribuições para a construção do seu conceito de geopolítica, bem como sua concepção de Estado. O sociólogo sueco tinha muitos estudos sobre outras áreas do conhecimento e, em boa parte, dedicava-se à leitura do pensamento filosófico idealista alemão de Georg Friedrich Hegel e Johann Gottich. No campo dos estudos historiográficos, Kjellén também lia escritores alemães como Leopold Von Ranke. Outra área importante sobre a qual Kjellén se debruçou era a biologia, sobretudo do naturalista britânico Charles Darwin na sua obra A Origem das Espécies, de 1859 (Darwin 2002), que ocasionou uma série de desdobramentos, sobretudo o darwinismo social. Na virada do século XIX para o século XX já se encontravam nas análises das ciências humanas e sociais, e não apenas ao campo das ciências biológicas a ideia positiva de uma competição na qual os indivíduos mais fortes deveriam prevalecer em detrimento dos mais fracos. Essa ideia também fora aplicada aos Estados, visto sua analogia orgânica. Mais tarde, essa interpretação seria utilizada como discurso para ratificar a condução dos Estados no processo nacionalista, imperialista e nas Grandes Guerras Mundiais.

Por fim, uma quarta linha de estudos, fruto de seu trabalho acadêmico, foi no campo da geografia, que tinha entre seus principais expoentes os geógrafos alemães Karl Ritter e Friedrich Ratzel (Holdar 1992, 310) e o francês Vidal de La Blache. Foi a partir dos estudos de Friedrich Ratzel que se desenvolveram as doutrinas geopolíticas do geógrafo inglês Halford Mackinder, o geopolítico sueco Rudolf Kjellén e o general alemão Karl Haushofer (Moraes, 1990). Ratzel apresenta uma divisão da geografia em três vertentes: geografia física, biogeografia e antropogeografia. Essa última foi determinante para que esses autores se baseassem nos estudos da relação entre terra e homem. Segundo Ratzel, "as mútuas relações existentes entre a Terra e a vida, que sobre aquela se produz e se desenvolve, constituem precisamente o nexo entre uma e outra e, portanto, devem ser particularmente examinadas" (Ratzel 1990). A ideia de organicidade, portanto, permeará os estudos dos geógrafos posteriores a seu pensamento. Especialmente para Kjellén, embora o autor tenha se baseado na geografia política de Ratzel, o sociólogo sueco travará uma inovação entre essa última e a geopolítica ao incorporar o componente da política à relação "Terra e vida": "Como ciência política, ela (a geopolítica) tem sempre em vista o Estado como uma unidade e contribui para o entendimento de sua natureza; enquanto a geografia política estuda a terra como sede de comunidades humanas, em relação a seus outros atributos" (apud Couto e Silva 1967, 161).

Como observado, a pluralidade disciplinar em que Kjellén baseou seus estudos lhe proporcionou uma abrangência analítica. A confluência entre filosofia, história, biologia e geografia permitiu ao autor encontrar bases 
para a organicidade de sua definição do Estado, em que o mesmo aparece quase como uma unidade possuidora de um corpo (território) e uma alma (nação) (Holdar 1992, 312; Lundén 1986). Kjellén, ao trabalhar com esse conceito de Estado, buscou reconstruir os fatores que o compõe, tal como grupos sociais, territórios e recursos naturais. E tal como um organismo, também possui suas necessidades, expressadas por meio de seu caráter expansionista. Assim, um Estado não possui uma política expansionista porque deseja, mas porque necessita. Trata-se, portanto, de uma condição determinística, ao passo que o Estado para se tornar forte é obrigado, por sua natureza, a ser expansivo (Lundén 1986). O Estado se torna escravo de seu território e torna-se um ser vital, assim como outros organismos biológicos, dotado de vida própria e necessidades relativas à sua condição orgânica (Mello 1997).

Uma vez que o conceito de Estado passa a ser denominado pelas suas características determinísticas, isto é, pelo que está fadado a acontecer, Kjellén direciona o campo da geopolítica mais para perto da Ciência Política ao invés da Geografia. O Estado enquanto organismo possui poder, mas essa definição só pode ser relacional, ou seja, comparada ao poder dos outros Estados (Holdar, 1992). Por isso, em boa parte de suas obras, Kjellén se atenta para a discussão do papel desempenhado pelos Estados, em especial das grandes potências, dentro da lógica territorial enquanto pré-condição determinística.

Desse modo, Kjellén, ao elaborar o conceito de geopolítica e situá-lo mais no campo da Ciência Política em relação aos aspectos metodológicos, buscará afirmar uma nova forma de conceber o Estado e, por conseguinte, a Política:

Kjellén é, além do criador fulgurante de uma nova doutrina de Estado, seu formidável e meticuloso sistematizador. [...] Seu sistema, apresentado em esboço desde 1908 nas preleções feitas na Universidade de Gottemborg, é revisto outra vez, e outra vez apresentado em linhas mais harmônicas, por isso mais simétricas, no citado pequeno volume de 1920. É então que passa a falar, com insistência e precisão, de Política e não vagamente de uma Ciência do Estado, teórica. Insiste no caráter prático, concreto, objetivo da Política, pois deseja vê-la ocupando-se do "Estado como ele ê", e não abordando princípios vagos, imprecisos, e mais ou menos idealísticos. Para isso, fixa nitidamente o conceito que deseja conferir à Política, bem como a sua linha de demarcação com outras ciências e os contornos internos de uma subdivisão orgânica que mantenha a unidade na variedade.

A Política conserva para ele - é claro - seu velho caráter de arte de governar os povos, mas a estes ele os vê constituindo os vários 
Estados da Terra como "agentes" da história do mundo [ .... Na corrente de Hubner Droysen, considera que a Política não ensina como deve ser o mundo, os Estados em geral, e cada Estado em particular, mas como são de fato e como podem ser. (...) A Política será, melhor dizendo, a "ciência dos estadistas", dos homens que por lidarem com a realidade das coisas dela precisam tomar conhecimento em seus duros aspectos efetivos (Backheuser 1952, p. 35-36, destaques no original).

A Política, portanto, segundo Kjellén, era a "teoria do Estado" (Holdar 1992). Além de se empenhar na leitura do papel do Estado frente às condições territoriais, Kjellén também desenvolverá um sistema de conceitos para analisar a relação entre os Estados de modo a tornar sua metodologia mais rica no que se refere aos aspectos mais detalhados das estruturas que compõem os atores estatais. Kjellén categoriza os atributos do Estado como: Geopolítica (estudo do território do Estado); Etno ou Demopolítica (estudo da população do Estado); Ecopolítica (caráter da economia do Estado); Sociopolítica (estudo da política societal) e, por fim, a Cratopolítica como estudo da política governamental-constitucional das massas (Mello 1997, pp. 35-36). Para o autor, a dimensão econômica, ética, social e jurídica eram fatores tão importantes quanto a dimensão territorial. Em outras palavras, para entender as demandas do Estado e sua posição política, a análise deve ser feita por meio das cinco categorias para conceber a doutrina do Estado como um organismo geográfico que, dentro de seu território dispõe de características e relações inseridas na dimensão espacial (Edström et al. 2014).

Ao se pensar o Estado como um território e nação, Kjellén também articula suas análises a partir da relação entre nacional e internacional, uma vez que sua própria definição de política e Estado possui um recorte fronteiriço. Ao analisar as cinco categorias, o jurista sueco dispõe de uma análise dentro do escopo espacial do Estado, isto é, a partir de uma dimensão nacional. Mas a condição vital do Estado é uma condição relacional, a sua preservação perante os demais Estados, trazendo, portanto, uma dimensão internacional (Edström et al. 2014). Tanto que suas obras buscam compreender o papel e as estratégias da Suécia perante os desdobramentos conjunturais mundiais. Outro fator estudado foi o papel da Suécia e sua importância geopolítica para a Europa, especialmente na sua relação com a Alemanha, pois destacava a importância desse país no continente europeu. Já em âmbito mundial, a análise referente à Primeira Guerra Mundial se tornou uma das peças mais importantes para a estratégia dos países em meio a um conflito em escala global.

A Primeira Guerra Mundial proporcionou bases sólidas para o conceito ganhar importância na Europa, haja vista a rivalidade entre as grandes 
potências, já estudada no livro de Kjellén Stormakterna (1912). Nessa obra, o jurista sueco já apresentava os indícios dos contornos da política das potências consideradas importantes no cenário internacional da virada do século XIX e começo do século XX, com foco na França e na Alemanha. Durante a eclosão da Primeira Guerra Mundial, Kjellén apresenta, em seu livro de 1915, Världskrigets politiska problem (Os problemas políticos da guerra mundial) (Kjellén 1915), alguns problemas que provocaram o grande conflito mundial, tal como a trajetória política no pré-guerra. Segundo o jurista sueco, alguns países como Rússia, Inglaterra, França, Estados Unidos e Alemanha seriam as grandes potências, as quais se inserem no mapa político delineado por diferentes interesses vitais desses mesmos Estados. Os dois últimos países representariam um poder em ascensão; a Alemanha, em especial, deteria o status de potência mundial do futuro framtidens världsmakt (Kjellén 1915, 168), um poder capaz de modificar o jogo político na Europa.

Toda a preocupação de Kjellén com a política internacional das grandes potências no que se reflete no conceito de geopolítica teve repercussões para além da Suécia. De fato, o termo geopolítica passou a se difundir a partir do final da Primeira Guerra Mundial, aliado ao fato de que na Europa se exacerbava uma política imperialista, e a posição territorial dos Estados poderia favorecer (ou não, dependendo de seus interesses) o lugar ocupado por esses países na política continental. Na Alemanha, em especial, o termo ganhou um significado especial, mais tarde com o nazismo. As ideias de Kjellén, que tinham uma conotação conservadora na Suécia, ganharão espaço na Europa, sobretudo na Alemanha, por meio de seu intérprete, o general Karl Haushofer.

A disseminação do conceito de geopolítica na Alemanha: a importância de Karl Haushofer

O conceito de geopolítica rapidamente ganhou espaço na Europa. Logo após a Primeira Guerra Mundial, o termo passou a ser utilizado largamente nos meios acadêmicos e políticos. Além do general alemão Karl Haushofer, teóricos alemães como os geógrafos Otto Maull, Erich Obst e Hermann Lautensach; o cientista político Adolf Grabowsky (cofundadores e coeditores da revista geopolítica alemã Zeitschrift für Politik); o jurista e filósofo político Carl Schmitt, e linguista Heinz Kloss promoveram discussões sobre a geopolítica nas diferentes áreas acadêmicas. Entre os políticos, se destaca Rudolf Hess - um dos principais fundadores do Partido Nazista e responsáveis por ajudar a incorporar a ideia de espaço vital na Alemanha de Adolf Hitler (Couto e Silva 1967).

A excessiva exaltação do papel da Alemanha por Kjellén fez com que rapidamente a geopolítica de origem sueca derivasse na perspectiva ger- 
mânica, ao incorporar a ideia do Lebensraum à definição de Estado - conceito alemão preconizado por Ratzel no final do século XIX que significa "espaço vital” -, desdobrada da noção de uma perspectiva estratégica expansionista da geopolítica enquanto garantidora dos interesses orgânicos do Estado. O termo geopolítica e a nova interpretação de Estado desembarcaram na Alemanha para que esse país fosse palco da concretização das estratégias geopolíticas propostas pelo jurista sueco.

O conceito de geopolítica na Alemanha foi introduzido pelo general, jornalista, político e professor de geografia política e história militar alemão Karl Ernst Haushofer (Mello 1997). Ele foi o precursor das ideias de geopolítica na Alemanha no período entreguerras, marcando definitivamente a importância da posição política alemã no mundo. Mais do que teoria, a geopolítica era uma diretriz política para a Alemanha afirmar seu poder perante os demais países (Hervig 1999, 218). E o papel da Alemanha no conflito mundial abriu uma lacuna no pensamento político e estratégico do país. A Alemanha havia sofrido uma derrota na Primeira Guerra, e posteriormente se sujeitou às cláusulas do Tratado de Versalhes. Do ponto de vista interno, a fragilidade da República de Weimar, assim como a ascensão do nacional-socialismo permitiram a ascensão das concepções geopolíticas do general Karl Haushofer (Mello 1997, 38).

Karl Haushofer foi um importante personagem na história da Alemanha, uma vez que delineou boa parte das estratégias geopolíticas germânicas depois da Primeira Guerra Mundial. Seu ingresso no Exército, em 1887, propiciou um olhar mais estratégico para a Alemanha, sobretudo no decorrer da Primeira Guerra (Hervig 2013, 222). O interesse pela organização política e militar dos países orientais guiou Haushofer a uma viagem ao Japão, China e Coréia para estudar as estratégias e a estrutura de poder desses países. Assim, suas observações entre 1908 e 1910 sobre as estratégias militares, especificamente no Japão, foram importantes para organizar a tropa alemã nos campos de batalha da Primeira Guerra Mundial (Hervig 1999, 222; Mello 1997, 38), uma vez que o geopolítico alemão também era major-general. Tal expertise também permitiu a Haushofer ingressar na Universidade de Munique onde se formaria em 1913, tornando-se, à semelhança da trajetória de Kjellén, professor de geopolítica na mesma universidade. Seu estudo sobre a estratégia da guerra permitiu a Haushofer transitar entre os esboços teóricos da geopolítica e as diretrizes da práxis por meio do Exército. Haushofer apresentou sua tese de doutorado na Universidade de Munique abordando uma leitura geopolítica sobre o Japão (Hervig 2013, 222), e seu interesse pela geografia, associada às constantes leituras do geógrafo alemão Friedrich Ratzel, garantiu ao general alemão um cargo como docente na Universidade de Munique, o que mais tarde lhe 
ajudou a criar a linha de pesquisa da geopolítica alemã, denominada por alguns teóricos por "Escola de Munique"s (Herwig 1999).

O general alemão em 1916 teve contato, pela primeira vez, com a obra de Kjellén, e desse estudo buscou aprimorar suas estratégias a partir da leitura dos textos do jurista sueco (Hervig 1999, 238). Desde então, o general alemão se aproximou da temática, buscando aprimorar o conceito de geopolítica para o contexto da Alemanha e seus interesses políticos. Escreveu mais de 40 livros e cerca de 400 artigos sobre os estudos de Kjellén, Ratzel, Mackinder, entre outros (Herwig 1999, 221).

A projeção teórica de Haushofer se deu sobretudo a partir da inauguração da revista de geopolítica, em janeiro de 1924 intitulada Zeitschrift für Geopolitik. Ancorado no conceito de geopolítica introduzido por Kjellén,

A fundação de um periódico mensal em janeiro de 1924, o Zeitschrift für Geopolitik, dedicado exclusivamente ao cultivo deste assunto, testemunha o interesse generalizado que foi agitado pelo trabalho de Kjellén. O professor Karl Haushofer de Munique, o editor, anuncia com franqueza que o objetivo deste jornal é encorajar investigações ao longo das linhas traçadas por Ratzel e Kjellén. Ele define Geopolitik como "a ciência das formas políticas da vida em suas relações regionais, nas suas relações com a superfície da Terra e influenciada pelos movimentos históricos" (German Political Geography $1925,340-341)$.

A revista Zeitschrift für Geopolitik inaugurou a produção teórica da chamada Escola de Munique (ou Instituto de Munique), tendo como objetivo tratar os assuntos do Estado a partir da fusão da área da Geografia com a Ciência Política. O editor-chefe foi Karl Haushofer, o que lhe permitiu intensificar seus estudos acerca da geopolítica. Em 1928, na obra Bausteine zur Geopolitik, Haushofer já havia amadurecido seus estudos sobre a geopolítica e explicitado sua própria definição. Segundo o general alemão, geopolítica é "a doutrina das relações espaciais de desenvolvimentos políticos ... com base nos fundamentos gerais da geografia, particularmente na geografia política, como a doutrina dos organismos espaciais políticos e sua estrutura" (Haushofer 1928 apud Herwig 1999, 219, tradução livre). Com essa definição, Haushofer buscará balizar os fundamentos da geografia e da política a partir de uma dimensão espacial, enfatizando a importância das fronteiras, ao passo que a Alemanha, nesse momento histórico, vivenciava um momento político conturbado.

Além de Kjellén, Haushofer também buscou nos estudos de Friedrich Ratzel a relação entre geografia e política, conforme se vê na análise a seguir: 
Foram fontes importantes de inspiração para o principal teórico geopolítico e general militar, Karl Haushofer. No momento da sua visita à Suécia em 1935, Haushofer estava prestes a publicar a $25^{\mathrm{a}}$ edição alemã de Die Grossmächte de Kjellén [As Grandes Potências, em tradução livre]. A ideia de que os Estados não eram entidades jurídicas fixas, mas organismos dinâmicos que competiam na cena internacional, era algo que apelava para Haushofer. Ele deveria fundir esse pensamento com o conceito de Lebensraum de Ratzel, que mais tarde alcançaria Hitler (Tunander 2001, 451).

Neste diapasão, a publicação do prefácio de Haushofer na $25^{\mathrm{a}}$ edição, em 1935, do livro Stormakterna (Die Grossmächte, em alemão), de autoria de Kjellén, foi um dos primeiros indícios de seu interesse pela geopolítica, tanto que foi uma importante fonte teórica para aprimorar a ideia do Lebensraum, já preconizada por Ratzel. E, assim como Ratzel e Kjellén, Haushofer associou algumas áreas do conhecimento, como Geografia e História.

Sua experiência no exército proporcionou uma leitura geopolítica mais aproximada da estratégia a qual o Estado deveria seguir para buscar seus interesses vitais. Apesar de ter-se fascinado pelos estudos do Japão e o extremo oriente,

A matriz teórica da doutrina de Haushofer deve ser buscada, por outro lado, na geografia política de Ratzel, na geopolítica de Kjellén e, principalmente, na teoria do poder terrestre de Mackinder, cujas ideias constituem o núcleo central da proposta de edificação de um bloco eurasiático sob a direção da Alemanha nazista (Mello 1997, 38).

A centralidade de Haushofer estava, portanto, na Eurásia, ${ }^{4}$ e a Alemanha seria a responsável por conduzir a coalizão com a União Soviética, conquistando o poder e a primazia na região. No entanto, apesar do pensamento geoestratégico de Haushofer oferecer um papel de protagonista à Alemanha, as ideias do geopolítico não se tornaram automaticamente as diretrizes da política nazista na Alemanha. Isso porque a trajetória pessoal e política de Haushofer é deveras complexa e se funde com os fatos históricos marcantes da Alemanha nazista.

A vida de Haushofer fora marcada por importantes conexões com a política, o exército e a academia. Estudar a geopolítica e sua difusão na Alemanha é também acompanhar a trajetória da vida pessoal e política do general alemão. No entanto, apesar da tarefa de reconstituir esse caminho metodológico que conecta "vida e obra", muitos relatos biográficos são inconclusivos, ao passo que a reconstrução histórica fidedigna sobre seu passado, principalmente sua suposta conexão com o partido nazista possui 
diversas lacunas e, portanto, muitas das afirmações devem ser revisadas e comprovadas. Para apresentar tais conexões, no entanto, apresentaremos algumas conjecturas.

Muitos fatos sobre a época em que Haushofer ganhou notoriedade política e acadêmica se passam nos períodos que antecedem à ascensão de Adolf Hitler no poder até o ano em que se suicida em 1946. Esses dados históricos, no entanto, ainda são desconhecidos, inclusive se Haushofer e Hitler tinham uma proximidade a ponto de deduzir uma possível influência política do geopolítico alemão sobre o governo nazista. Recentemente alguns documentos vieram à tona. Segundo o jornal alemão Die Welt, em 2010 cerca de 500 documentos foram encontrados e leiloados da casa de leilão Fürth Behringer, como dados do ingresso de Hitler na prisão em Landsberg, bem como os registros de visitantes ao Führer durante seu encarceramento $^{5}$ (Kellerhoff 2010). Por tratar-se de documentos que foram comprados e, portanto, de posse particular, há algumas especulações sobre as visitas a Hitler na prisão que poderão se confirmar somente se esses documentos se tornarem totalmente públicos. ${ }^{6}$

A vida política de Haushofer começara a se transformar em 4 de abril de 1919, ano em que ele dá aulas de geopolítica na Universidade de Munique a Rudolf Hess (Hervig 1999, 224) - um dos protagonistas na criação do nacional-socialismo, partido de Adolf Hitler, chegando ao posto de vice-Führer da Alemanha no período do regime nazista. O interesse de Hess pela geopolítica e o conceito do Lebensraum o ajudaram a pensar um papel de protagonista para a Alemanha após o Tratado de Versalhes. Essa aproximação acadêmica rapidamente se converteu na aproximação pessoal entre Hess e Haushofer. Rudolf Hess foi um dos principais condutores das leis antissemitas na Alemanha. Hess se tornou amigo próximo da família Haushofer, inclusive de sua mulher de ascendência judaica Marta Mayer Doss. No entanto, apesar dessa ascendência, durante seu posto ativo como vice-Führer ele tentou resguardar a família durante seu período de maior influência no governo alemão, proibindo a SS de monitorá-los, prendê-los e executá-los (Herwig 1999). Hess também era próximo de seus dois filhos, Heinz e Albrecht Haushofer, tendo esse último se tornado mais tarde o assessor de Hess no regime hitleriano. Albrecht Haushofer se tornaria o principal seguidor da linha geopolítica e contribuidor do jornal que seu pai coordenara, Zeitschrift für Geopolitik, uma vez que também se tornou professor e passou a lecionar geopolítica na Universidade de Berlim. Albrecht Haushofer conciliou a vida acadêmica e vida política e se tornou o assessor de Hess, aprofundando os laços da família Haushofer com o poder na Alemanha. Morreu em 1945, meses antes que Hitler, marcando a história da Alemanha na Segunda Guerra Mundial ao lado de Rudolf Hess. 
Segundo o relato de seu filho, Wolf Rüdiger Hess, em maio de 1920 seu pai ouviu pela primeira vez o discurso de Hitler na cervejaria na Bavária e passou a fazer parte do grupo no dia $1^{\circ}$ de julho de 1920 (Hess, 1993). Foi então que Hess começou a participar do Partido Nazista, em 1920 (Hess, 1993), e imediatamente se aproximaram. Quando Hitler foi preso em 1923, os companheiros partidários, incluindo Hess, também o acompanharam. Um pouco antes de ingressar à prisão, ainda como aluno na Universidade de Munique, Hess já havia adotado Haushofer como seu mentor. Tendo quase o dobro da idade de Hess, Haushofer o tratava quase como um filho adotivo (Irving 2010, 7), a ponto do professor de geopolítica visitá-lo na prisão em Landsberg. Com relação a esse episódio muitos relatos biográficos se divergem.

A primeira fonte indica que Haushofer conheceu Adolf Hitler antes do golpe, quando foi abordado para ingressar no partido, mas recusou a proposta (Herwig, 1999). Outra fonte, como o Museu de História Alemã, explicita que o primeiro encontro de Haushofer e Hitler foi em 24 de julho de 1921 ocasião em que apresentou as ideias do Lebensraum (Deutsches Historisches Museum, s.d.) e que, portanto, a bagagem teórica geopolítica ajudou a compor um dos pilares político-estratégicos do governo nazista. Uma terceira versão apresenta uma aproximação direta entre Haushofer e Hitler. Segundo as informações do Departamento de Justiça de Landsberg apuradas por Hans-Adolf Jacobsen, biógrafo de Haushofer, o geopolítico e general alemão visitou Hitler na prisão entre 24 de junho e 12 de novembro de 1924, ensinando-lhe as teorias da geopolítica; os conceitos de Lebensraum, heartland e darwinismo social; e apresentando as obras de Ratzel - Politische Geographie (Geografia Política) e Carl von Clausewitz - Vom Kriege (Da Guerra), tanto para Hitler quanto para Hess (Herwig 1999). Durante as oito semanas de visita (sempre às quartas-feiras na parte da manhã e da tarde), no total de 22 horas de tutoria, Haushofer lhes teria ensinado sobre a geopolítica como a principal diretriz estratégica da Alemanha, principalmente para os políticos que almejavam ascender à liderança do país (Herwig 1999; Jacobsen 1979).

Uma quarta versão aponta que Haushofer visitou apenas Hess na prisão. Segundo David Irving (2010), biógrafo de Rudolf Hess, entre 24 de junho e 12 de novembro de 1924, Haushofer visitava Hess sempre às quartas de manhã e à tarde. No entanto, segundo suas pesquisas, apesar de suas visitas serem destinadas a Hess, Haushofer

também viu Hitler, mas enfatizou anos depois: "Minhas visitas a Landsberg foram destinadas a Hess, como ele era meu aluno". Na verdade, os visitantes não deveriam ver mais do que um prisioneiro e, na medida do possível, Hitler evitava ser abotoado pelo falante acadêmico. 
Para Hess, Haushofer trouxe livros para melhorar sua mente Karl von Clausewitz sobre a guerra e a segunda edição melhorada da Politische Geographie de Friedrich Ratzel - mas ele podia ver que nem Hess nem Hitler compreenderam o essencial da geopolítica apesar desses "tutoriais" privados. "Lembro-me bem," lembrou o professor em 1945, "que sempre que Hess entendia algo e tentava explicá-lo a Hitler, Hitler iria sair com uma de suas novas ideias sobre uma autoestrada ou algo completamente irrelevante, enquanto Hess ficava ali e nada mais dizia sobre isso" (Irving 2010, 12).

O fato é que todas essas versões apresentadas demonstram que, direta ou indiretamente, Haushofer teve contato com Hitler, seja na forma de tutoria mais incisiva, seja por meio de seu pupilo. Rudolf Hess, portanto, foi o elo entre o mundo acadêmico de Haushofer e o mundo político de Hitler. Hess era amigo de Haushofer e braço direito de Hitler. Compreendia a teoria da geopolítica e tentava aplicá-la na práxis política. E seus ensinamentos sobre a geopolítica certamente foram cruciais para algumas determinações governistas após a ascensão do nazismo ao poder. A influência dos estudos de Kjellén estava evidente nas diretrizes políticas alemãs. Tanto que, em 14 de maio de 1935, Rudolf Hess viaja a Estocolmo para discursar sobre as relações estabelecidas entre a Suécia e a Alemanha. Em sua arguição, Hess ressalta a importância dos estudos suecos, em especial de Rudolf Kjellén para as necessidades da Alemanha e como esse estudo foi importante para seu mentor, Karl Haushofer, a quem também homenageia em suas palavras (Hess 1935).

Para que se possa indagar mais sobre a geopolítica na Alemanha, deve-se compreender também o elo que existe com seu mentor político no período nazista: Adolf Hitler. A relação de Hess estabelecida com Hitler desde 1920 (HESS 1993, 3-4) foi importante para a construção do regime nazista na Alemanha, e seu pilar teórico e político iniciou-se na publicação na obra de Hitler, o Mein Kampf (Minha Luta), escrita em 1924 (Hitler 1939) na prisão, ao qual algumas interpretações sugerem a influência de Haushofer e sua teoria geopolítica à obra de Hitler. Segundo o relato do filho de Rudolf Hess, Wolf Rüdiger Hess,

Foi durante esse período de encarceramento que Hitler e meu pai estabeleceram o relacionamento especial de confiança e confiança mútua que marcou a imagem da liderança do partido em anos posteriores. Foi também em Landsberg que Hitler escreveu seu bem conhecido trabalho seminal, Mein Kampf $\llbracket$ Minha Luta, em tradução livre]. Meu pai editou as páginas do manuscrito e verificou-os quanto a erros. Hitler foi libertado no início de 20 de dezembro de 1924. Quatro meses depois, em abril de 1925, meu pai tornou-se o secretá- 
rio particular de Adolf Hitler, com um salário mensal de 500 marcos (Hess 1993, 6).

A partir dessa aproximação, Hess passa a ser vice-Führer do regime nazista, o que lhe garantia certo prestígio político. Seus estudos sobre geopolítica ajudariam a compreender melhor o papel da Alemanha no cenário entre guerras, o que contribuiu para difundir sua doutrina política também a outros países, como a Itália. Ainda que não se comprove os reais fatos sobre a relação explícita entre Haushofer-Hess-Hitler, bem como a influência direta das teses geopolíticas em Mein Kampf, o fato é que aparece em uma única passagem explicitamente o conceito de geopolítica:

Se alguém não quer perder a uniformidade da doutrina, esta subdivisão deve ocorrer somente após a autoridade do fundador espiritual e a escola que ele convocou para a vida puder ser considerada como reconhecida. Em relação a isso, a importância geopolítica de um centro de um movimento não pode ser superestimada. Somente a presença de um centro e de um lugar, banhada pela magia de uma Meca ou de uma Roma, pode, por fim, dar um movimento que força que está enraizado na unidade interior e no reconhecimento de uma cabeça que representa essa unidade ${ }^{7}$ (Hitler 1941, 481-482, destaque nosso).

Hitler utilizará tangencialmente o conceito de geopolítica ao discutir sobre o desenvolvimento do Partido Nacional Socialista, pois diante de uma sociedade alemã fragmentada era necessária a criação de um núcleo central de comando que deveria se situar em Munique. Na ordem de seu pensamento, a discussão sobre o partido deveria anteceder ao tema sobre o significado de Estado. Apesar de mencionar o termo geopolítica em apenas uma ocasião, o conceito de Lebensraum será mais bem desenvolvido, uma vez que o mesmo está vinculado à análise que Hitler faz sobre o Estado como um organismo vivo, tal como a geopolítica defende:

Um Estado pode ser considerado como um exemplo modelo se servir adequadamente não apenas as necessidades vitais do estoque racial que representa, mas se ele realmente assegura, por sua própria existência, a preservação desse mesmo estoque racial, independentemente do significado cultural geral que esta instituição estatutária pode ter nos olhos do resto do mundo. Pois não é tarefa do Estado criar capacidades humanas, mas apenas garantir espaço livre para o exercício de capacidades que já existem. Por outro lado, um Estado pode ser chamado de ruim se, apesar da existência de um alto nível cultural, condiciona a destruição dos portadores dessa cultura, rompendo sua uniformidade racial. Pois o efeito prático de tal política seria destruir as condições que são indispensáveis para a existência posterior dessa 
cultura, que o Estado não criou, mas que é fruto do poder criativo inerente ao estoque racial cuja existência é assegurada por estar unidos no organismo vivo do Estado. Mais uma vez, deixe-me enfatizar o fato de que o próprio Estado não é a substância, mas a forma (Hitler 1939, 366 , destaque nosso).

Tal como defende o Estado como um organismo vivo na obra Mein Kampf, o conceito de Lebensraum era crucial para que a geopolítica se transformasse de um postulado teórico em uma diretriz política. Em outras palavras, a geopolítica alemã seria o estopim para a cisão ideológica no mundo, as alianças criadas pelos seus líderes estatais e a tentativa de imposição de poder a partir de uma chamada "necessidade vital" dos Estados em um processo natural e determinístico dos mesmos, defendido por essa doutrina.

\section{CONSIDERAÇÕES FINAIS}

Ao se considerar a cronologia histórica do conceito, a ideia de geopolítica aparece pela primeira vez na Suécia pelo professor e geopolítico Kjellén e ganha notoriedade na Alemanha por Haushofer, no campo acadêmico, e por Hess, no campo político, ao passo que se torna estratégica na consecução do nazismo e na defesa do determinismo do Estado, mais precisamente da Alemanha enquanto merecedora de um papel central de anexação de territórios para sua própria sobrevivência, segundo os preceitos nazistas.

A geopolítica, portanto, marcará profundamente os rumos do período das duas Guerras Mundiais e desembocará com maior nitidez na Segunda Guerra Mundial, ao tornar-se notória não apenas na Suécia, o Estado embrionário, ou na Alemanha, palco do acirramento das tensões mundiais, mas também em outras partes do mundo, servindo de inspiração para novas formas políticas.

Esse artigo, portanto, buscou resgatar a gênese da geopolítica a partir de uma dimensão história de seus principais personagens - Rudolf Kjellén e Karl Haushofer - responsáveis, respectivamente, por cunhar o termo academicamente e por expandi-lo politicamente. O objetivo de trazer os dados históricos para a análise da genealogia da geopolítica foi de enfatizar a importância da dimensão do tempo e espaço de uma concepção teórica, ou seja, da importância de se estudar o quando e onde se produz tal política.

\section{REFERÊNCIAS}

ALMAGIÀ, Roberto. 1933. "Kjellén, Johan Rudolf." Enciclopédia Italiana. Enciclopédia Treccani. 1933. Disponível em: <http://www.treccani.it/enciclopedia/johan-rudolf-Kjellén_(Enciclopedia-Italiana)/> Acesso em: 11 out. 2017. 
BACKHEUSER, Everaldo. 1952. A geopolítica geral e do Brasil. Rio de Janeiro: Biblioteca do Exército.

COUTO E SILVA, Golbery. 1967 Geopolítica do Brasil. Rio de Janeiro: José Olympio.

DARWIN, Charles. 2002. A Origem das Espécies, Belo Horizonte: Itatiaia.

DEUTSCHES HISTORISCHES MUSEU. S.d. LEMO - Lebendiges Museum Online (blog). Disponível em: <https://www.dhm.de/lemo/biografie/karl-haushofer>. Acesso em: 02 mai. 2017.

EDSTRÖM, Bert, BJÖRK, Ragnar e LUNDÉN, Thomas. 2014. Rudolf Kjellén: geopolitiken och konservatismen. Stockholm: Hjalmarson \& Högberg Bokförlag.

FRIEDMANN, Jan. 2010a. "ZEITGESCHICHTE Fans Auf Dem Feldherrenhügel.” Der Spiegel, June 21, 2010. Disponível em: <http://www.spiegel.de/spiegel/print/d-7 1029986.html>. Acesso em: 24 set. 2017.

FRIEDMANN, Jan. 2010b. “As Mordomias de Hitler Na Prisão.” O Estado de S. Paulo. 27 de Junho de 2010. Disponível em: <http://internacional.estadao.com. $\mathrm{br} /$ noticias/geral,as-mordomias-de-hitler-na-prisao-imp-,572725>. Acesso em: 26 out. 2017.

German Political Geography. 1925. Geographical Review, v. 15, n. 2, p. 340-341.

HERWIG, Holger H. 1999. "Geopolitik: Haushofer, Hitler and Lebensraum." Geopolitics, geography and strategy, v. 22, n. 2-3, p. $218-241$.

HESS, Rudolf. 1935. "Rede von Herrn Reichsminister Hess AM 14. Mai 1935 in Der Deutsch-Schwedischen Gesellschaft in Stockholm." Discurso, Stockholm. Disponível em: <https://archive.org/stream/RedeInStockholmAm 14.Mai 1935/ HessRudolf-RedeInStockholmAm14.Mai193510S._djvu.txt>. Acesso em: 13 dez. 2017.

HESS, Wolf Rüdiger. 1993. "The Life and Death of My Father, Rudolf Hess." Institut of Historical Review, The Journal of Historical Review, v. 13, n. 1, p. 24-39.

HITLER, Adolf. 1939. Mein Kampf. [S.l, s.n.]

HITLER, Adolf. 1943. Mein Kampf. Munique, Alemanha: Franz.

HOLDAR, Sven. 1992. "The ideal state and the power of geography. The life-work of Rudolf Kjellén." Political Geography, Political geographers of the past IX, v.11, n. 3, p. 307-23. 
IRVING, David. 2010. Hess: The missing years 1941-1945. Dorney, Windsor: Focal Point Publications.

JACOBSEN, Hans-Adolf. 1979. Karl Haushofer: Leben und Werk. 2 v. Boppard: Harald Boldt.

KELLENHORFF, Sven Felix. 2010. "Liste mit Hitlers Gefängnisbesuchern wird versteigert|.”. Die Welt. Disponível em: < https://www.welt.de/kultur/article8429238/Hitler-Akten-aus-Landsberg-beschlagnahmt.html>. Acesso em: 29 abr. 2018.

Kjellén, Rudolf. 1899. “Studier Öfver Sveriges Politiska Gränser.” Ymer, v. 3, p. 283-331.

Kjellén, Rudolf. 1912. Stormakterna: Konturer Kring Samtidens Storpolitik. Stockholm: Hugo Gerbers Förlag.

Kjellén, Rudolf. 1913. Den ryska faran. Universidade de Wisconsin - Madison: Karlskrona-tidningen.

Kjellén, Rudolf. 1915. Världskrigets politiska problem. Goteborgs; Stockholm: Albert Bonniers Förlag.

Kjellén, Rudolf. 1924. Der Staat als Lebensform. Berlim: Kurt Vowinckel Verlag.

LEES-SMITH, H.B. 1923. "The Parliamentary System in Norway." Journal of Comparative Legislation and International Law, Third Series, n. 5, v. 1, p. 35-46.

LEWIN, Leif. 2008. "Demokratin Som Övergångsfas.” Svenska Dagbladet. March 10, 2008. Disponível em: <http://www.svd.se/demokratin-som-overgangsfas>. Acesso em: 27 de jul. 2015.

LUNDÉN, Thomas. 1986. "Political geography around the World VI: Swedish contributions to political geography." Political Geography Quartely, v. 5, n. 2, p. 181-186.

MELLO, Leonel Itaussu Almeida. 1997. A Geopolítica do Brasil e a Bacia do Prata. Manaus: Universidade do Amazonas.

MORAES, Antonio Carlos Robert. 1990. “Introdução.” In: Ratzel, São Paulo: Ática.

MURPHY, David Thomas. 2014. "Hitler's Geostrategistic? The Mith of Karl Haushofer and the 'Institut Für Geopolitik." The Historian, v. 76, p. 1-25. 
NEUMANN, Franz. 2009. Behemoth: The Structures and Practice of National Socialism 1933-1944. Chicago: Ivan R. Dee.

RATZEL, Friedrich. 1990. Ratzel. São Paulo: Ática.

TUNANDER, Ola. 2001. "Swedish-German geopolitics for a new century: Rudolf Kjellén's 'The State as a Living Organism.” Review of International Studies, v. 27, n. 3 , p. $451-463$. 


\section{NOTAS}

1. O trecho em sueco em que aparece a expressão "ponto de vista geopolítico" na revista Ymer em 1899: "A descrição que foi deixada vai fazer com que procuremos na direção de um background histórico e de direito populacional dar uma descrição de conjunto de nossas três principais fronteiras, para que de agora em diante se possa apreciá-las de um ponto de vista antropogeográfico ou, como eu preferiria dizer - do ponto de vista geopolítico. Os propósitos são, portanto que, nas condições suecas, e com base numa investigação estritamente empírica, se ponha em prática as sugestões que Ratzel tinha dado em Antropogeografia I (1882) e Geografia Política (1897)” (Kjellén 1899, destaque nosso, tradução livre).

2. No século XVII, a Rússia impôs seu domínio na Grande Guerra do Norte, que até então tinha a Suécia a liderar a região escandinava. No entanto, com o Tratado de Vestphália em 1648, a Suécia retoma seu status e passa a deter províncias como a Noruega (Lees-Smith 1923)

3. Há algumas controvérsias sobre a existência da Escola de Munique ou Instituto de Geopolítica. Para David Thomas Murphy não há dados concretos de sua existência (MURPHY 2014, 2). Já Franz Neumann discorda de tal visão, uma vez que suas ideias tiveram um alcance para além da academia, foi uma diretriz política na Alemanha (Neumann 2009, 137-138).

4. Seu "coração continental" ou "heartland", segundo o geógrafo inglês Halford Mackinder no início do século XX, seria estratégico para se atingir a primazia de poder de um Estado perante os demais, alterando assim o equilíbrio de poder mundial. O bloco eurasiano é uma massa terrestre transcontinental que engloba a Europa e a Ásia (apud Mello 1997, 21-37).

5. Provavelmente esses documentos foram extraviados pelo então diretor da prisão Otto Leybold (Friedmann 2010a, 2010b).

6. Os nomes publicados, por enquanto, são de Erich Ludendorff (estrategista do governo nazista), seu conselheiro, Dr. Frick e Alfred Rosenberg, arquiteto, e o que seria o futuro Ministro do Interior. Quanto aos parceiros carcerários estão Friedrich Weber, Hermann Kriebel, Emil Maurice e Rudolf Hess (Friedmann 2010a, 2010b), sendo esse último importante personagem quem será a conexão de Hitler com Haushofer, ainda que indiretamente.

7. Ressalte-se que nem todas as edições de Mein Kampf utiliza o termo geopolítica. Em algumas versões encontra-se o termo geográfica no lugar, o que acaba esvaziando, nesse caso, o sentido geopolítico da discussão. 


\section{A GÊNESE DA GEOPOLÍTICA E SUA DIFUSÃO NA HISTÓRIA MUNDIAL}

\section{RESUMO}

O objetivo do artigo é resgatar historicamente uma parte da genealogia da geopolítica, que se inicia na Suécia entre o final do século XIX e início do século XX pelo jurista sueco Johan Rudolf Kjellén, mas que ganha notoriedade mundial pelo general alemão Karl Haushofer, redefinindo, assim, a história da política mundial

Palavras-chave: Geopolítica; Genealogia; Rudolf Kjellén; Karl Haushofer.

\section{ABSTRACT}

The aim of the article is to rescue historically a part of the genealogy of geopolitics, which began in Sweden between the late nineteenth and early twentieth century by the Swedish jurist Johan Rudolf Kjellén, but gained worldwide notoriety by the German general Karl Haushofer, redefining in this way the history of world politics

Keywords: Geopolitics; Genealogy; Rudolf Kjellén; Karl Haushofer. 